\title{
Organochalcogen with Liquid Crystal Properties
}

\section{Tiago Frizon ${ }^{*}(P G)^{1}$, Hugo Gallardo(PQ $)^{1}$, Oscar Rodrigues $(P Q)^{2}$, Antonio Luiz $\operatorname{Braga}(P Q)^{1}$}

\author{
${ }^{1}$ Universidade Federal de Santa Catarina, UFSC, Florianópolis - Santa Catarina, Brasil \\ ${ }^{2}$ Universidade Federal de Santa Maria, Santa Maria, RS, Brasil \\ *tiagofrizon@gmail.com
}

Keywords: Liquid Crystal, organoselenium,1,3,4-Oxadiazole and 1,2,4-Oxadiazole.

\section{INTRODUCTION}

Important advances took place in the chemistry by using organoselenium, in the last decade. In the area of semiconductors, liquid crystals containing chalcogen atoms showed high mobility of charge in the mesofases ${ }^{1}$. The synthesis of organic materials, whether polymeric or molecular properties electroluminescent (OLED) is currently a wide area of research, involving interest academic and technological, with great potential application in electro-electronic industry, as displays of high brightness and flexibility? In this context, the objective is the synthesis of new compounds, liquid crystal containing heterocycles 1,2,4 - and 1,3,4 oxadiazole and selenium in its structure.

\section{RESULTS AND DISCUSSION}

To obtain the liquid crystalline organoselenetos was followed the schemes $\mathbf{1}$ and $\mathbf{2}$.

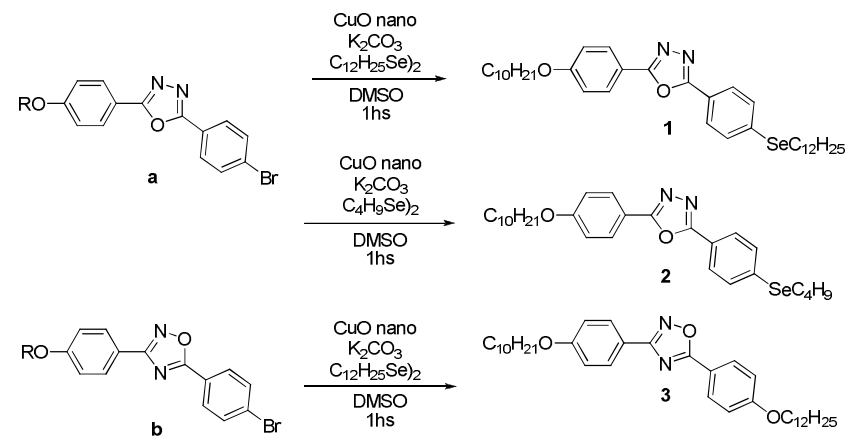

Scheme 1: Synthesis of organoselenetos 1, 2 and 3: i) $\mathrm{KOH}$, $\mathrm{CuO}$ nano, diselenide and DMSO.

The compounds 1,2 and 3 were obtained from the coupling reaction of intermediates $\mathbf{a}$ and $\mathbf{b}$ with two alkyl diselenide (dodecyl diselenide and butyl diselenide) with potassium hydroxide and $\mathrm{CuO}$ nano-particles as catalyst. The temperature of the reaction was kept $80^{\circ} \mathrm{C}$ under inert atmosphere for $1 \mathrm{~h}$.

For the synthesis of diselenide $\mathbf{4}$ and $\mathbf{5}$, elemental selenium, potassium hydroxide and $\mathrm{CuO}$ nano-particles as catalyst were used. The reaction proceeded in a similar manner as reported for the synthesis of selenides above.

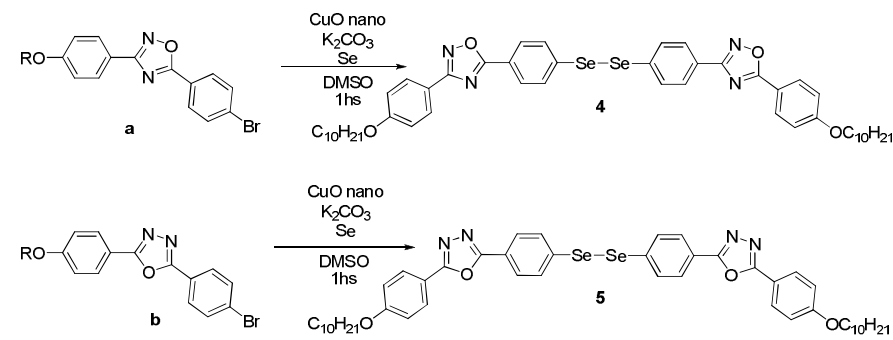

Scheme 2: Synthesis of organoselenetos 4 and 5: ii) $\mathrm{KOH}, \mathrm{CuO}$ nano, DMSO and elemental selenium.

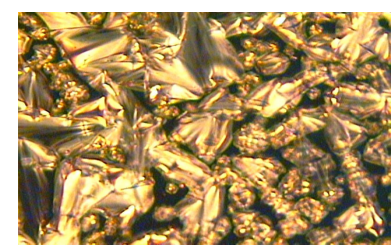

a)

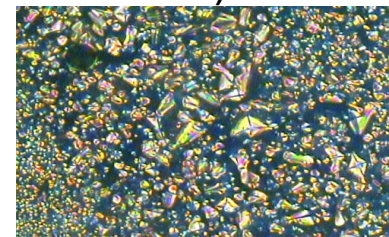

c)

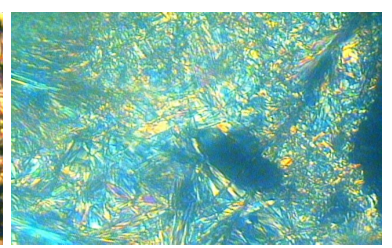

b)

d)

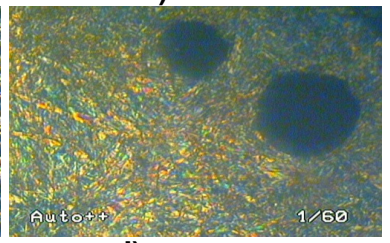

Figure 1: Textures representing mesophases displayed by compounds $1,3,4$ e 5 respectively.

\section{CONCLUSION}

This new class of organoselenetos, presents a strong blue luminescence, and mesomorphic smectic A. These compounds showed good thermal stability with decomposition temperature around $350^{\circ} \mathrm{C}$, suitable for applications in electronic devices.

The methodology was efficient for the proposal, with good yields.

\section{ACKNOWLEDGEMENTS}

CNPq, CAPES, FAPESC e INCT-catálise

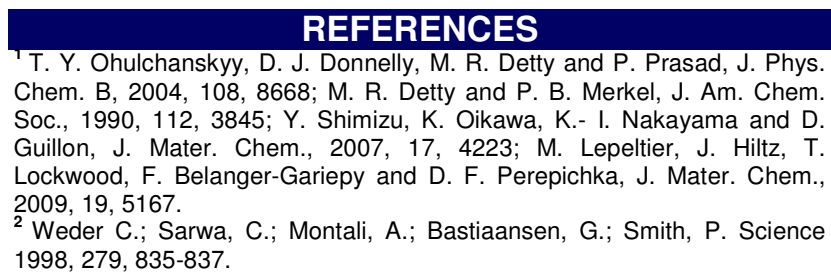

$14^{\text {th }}$ Brazilian Meeting on Organic Synthesis $-14^{\text {th }}$ BMOS - September 01-05, 2011-Brasilia, Brazil 